\title{
Raymond Trousson, Antoine-Vincent Arnault (1766-1834). Un homme de lettres entre classicisme et romantisme
}

\section{Franco Piva}

\section{(2) OpenEdition \\ Journals}

\section{Edizione digitale}

URL: http://journals.openedition.org/studifrancesi/33301

DOI: 10.4000/studifrancesi.33301

ISSN: 2421-5856

\section{Editore}

Rosenberg \& Sellier

\section{Edizione cartacea}

Data di pubblicazione: 1 décembre 2005

Paginazione: 651-652

ISSN: 0039-2944

\section{Notizia bibliografica digitale}

Franco Piva, «Raymond Trousson, Antoine-Vincent Arnault (1766-1834). Un homme de lettres entre classicisme et romantisme», Studi Francesi [Online], 147 (XLX | III) | 2005, online dal 30 novembre 2015, consultato il 19 avril 2021. URL: http://journals.openedition.org/studifrancesi/33301 ; DOI: https:// doi.org/10.4000/studifrancesi.33301

Questo documento è stato generato automaticamente il 19 avril 2021.

\section{cc) $($ ) $\ominus$}

Studi Francesi è distribuita con Licenza Creative Commons Attribuzione - Non commerciale - Non opere derivate 4.0 Internazionale. 


\title{
Raymond Trousson, Antoine-Vincent Arnault (1766-1834). Un homme de lettres entre classicisme et romantisme
}

\author{
Franco Piva
}

\section{NOTIZIA}

RAYMOND TROUSSON, Antoine-Vincent Arnault (1766-1834). Un homme de lettres entre classicisme et romantisme, Paris, Champion, 2004 («Les Dix-huitièmes siècles», 85), pp.

347.

1 Chi si ricorda più di Antoine-Vincent Arnault? Eppure all'epoca in cui egli visse, a cavallo tra Sette e Ottocento, Arnault godette di una grande notorietà sia nel campo della letteratura che in quello,più ampio, della politica o della mondanità. Celebre fin dall'età di venticinque anni, per una tragedia, Marius à Minturnes, che fu tra le più rappresentate e rappresentative del periodo rivoluzionario, Arnault entrò presto nell'intimità di Napoleone, di cui seguì da vicino tutta l'avventura con incarichi via via più prestigiosi, e di alcuni dei grandi protagonisti culturali di quell'epoca, da Talma, l'interprete di tutte le sue tragedie, a Mehul, il musicista con cui collaborò a più riprese, frequentò i salotti più in vista che animò con la sua loquela gradevole ed arguta nello stesso tempo, fu a lungo osannato come il vero erede di Corneille e di Voltaire, prima di diventare, come fabuliste, l'erede di La Fontaine. Perché il suo nome cadde presto nell'oblio? «Arnault a subi le sort des tard venus» spiega Trousson, che precisa: «Formé à l'école classique, admirateur inconditionnel de Corneille, Racine et Voltaire, il fut aussi - et le ridicule tue - des sept dramaturges qui demandèrent en 1829 à Charles $\mathrm{X}$ d'interdire le théâtre romantique sur les scènes de la Comédie-Française». Eppure Arnault non fu affatto un uomo arroccato, come lo furono altri al suo tempo, nella difesa di un passato ormai révolu. Ammirò Shakespeare quando quasi tutti in Francia lo disprezzavano: si lasciò sedurre dalla sua arte e dalle sue indimenticabili: figure alle quali si ispirò in alcune delle sue tragedie; fu sensibile alle possibilità del melodramma 
dal quale pure si fece tentare; prima di opporvisi, aprì anche la strada al dramma romantico, con una interpretazione libera delle regole classiche e facendo ricorso, per alcune delle sue tragedie, alla storia ed al colore locale, anche se fu vittima di uno stile che aveva ereditato da quel Settecento di cui rimase sino alla finee figlio. Arnault ad ogni modo non fu solo uno degli uomini più in vista e più osannati del suo tempo, specie nel periodo napoleonico, fu anche un personaggio di grande complessità, che meglio di altri forse incarnò le contraddizioni di un'epoca di passaggio quale fu quella in cui gli toccò di vivere. Bene ha quindi fatto R. Trousson, che recentemente ha ripubblicato i Souvenirs d'un sexagénaire, a ricostruire il persorso esistenziale e letterario di A.-V. Arnault: sulla base dei suoi preziosi Souvenirs certo, ma anche di una attenta lettura dei documenti d'archivio e, per l'attività letteraria, dei giornali dell'epoca, ricchissimi di testimonianze e di prese di posizione. Trousson ha accompagnato Arnault passo passo, dai promettenti inizi di Marius à Minturnes all'epoca della Rivoluzione - nei riguardi della quale l'ex segretario di Monsieur ebbe sempre un atteggiamento riservato se non proprio ostile - all'esaltante stagione rappresentata da Napoleone, dal quale Arnault fu affascinato fin dall'inizio ed a cui rimase sempre fedele, ai duri anni dell'esilio cui lo costrinse un vendicativo Luigi XVIII, fino al difficile e per certi versi patetico tentativo di ritrovare o rinnovare, in tempi ormai profondamente mutati, l'antica notorietà («Il ne pouvait pas admettre que son temps fût passé») ed alla sua sempre più pervicace opposizione a quel Romanticismo che, per certi versi, aveva egli stesso contribuito a far nascere (basti pensare ad opere come Don Pèdre, Oscar, Les Vénitiens o anche Le proscrit, rappresentata, tra molte polemiche, nel 1827).

2 Ne risulta, come dicevamo, un personaggio estremamente complesso ed interessante inserito in un contesto politico e culturale in piena anche se non sempre lineare evoluzione la cui conoscenza non potrà che favorire una più approfondita e corretta ricostruzione di un'epoca - quella dei primi trent'anni dell'ottocento - troppo spesso ingabbiata nella fin troppo comoda opposizione classicismo/romanticismo, e che ha invece bisogno - per essere colta nelle sue vere dinamiche - di essere letta ed interpretata con categorie un po' più articolate. Il bel volume di Trousson - che auspichiamo possa essere presto ristampato senza i numerosi refusi presenti in questa edizione - può costituire una buona base di partenza sia per la ricchezza delle informazioni che offre sia per la personalità stessa dell'uomo e dello scrittore di cui ci propone il ritratto. 